\title{
WELFARE IMPACT OF PRIVATE SECTOR INTERVENTIONS ON RURAL LIVELIHOODS: THE CASE OF MASVINGO AND CHIREDZI SMALLHOLDER FARMERS
}

\author{
Simon Munongo, Researcher \\ Great Zimbabwe University, Masvingo, Zimbabwe \\ E-mail: simonmunongo@gmail.com
}

Received September 21, 2012

\begin{abstract}
Improving livelihoods in rural areas is important to progress of the developing world and it helps in the creation of the domestic demand for the productive sector. Private sector partnerships in rural areas have been the major driver to reduction of market uncertainties and management of risk and thus bring development, these partnerships are done through private loans and contract farming in Zimbabwe. The major question however is do these partnerships increase rural household welfare in Zimbabwe or it is clearly a capitalist method of rural labour exploitation. Using Propensity Score Matching (PSM) method for rural communities in Chiredzi and Masvingo rural in Zimbabwe we found out that individual households that participates in contract farming and private loans have increased welfare gains than those that do not participate.
\end{abstract}

\section{KEY WORDS}

Contract farming; Household; Partnership; Propensity score matching; Private sector; Welfare.

As part of their effort to solve market failures that include information asymmetry and missing markets the private sector in Zimbabwe have devised a number of strategies in rural economic systems that include contract farming, business loans and infrastructural development. Contract farming is the most prevalent private sector partnership strategy in rural areas; it is defined as a situation when a processing firm delegates its production of agricultural commodities to growers.

The private sector market mechanisms are viewed as a means of improving the household welfare in developing countries but in Zimbabwe it has been a subject of debate with some quarters arguing that it is a means of private sector profiteering and rural labour exploitation whilst the private sector view it as a means of rural empowerment and a means of improving rural development, creating markets and bringing economic growth to the developing world.

Improving livelihoods in rural areas is important to progress of the developing world and it helps in the creation of the domestic demand for the productive sector. Private sector partnerships in rural areas have been the major driver to reduction of market uncertainties and management of risk and thus bring development, these partnerships are done through private loans and contract farming in Zimbabwe. The major question however is do these partnerships increase rural household welfare in Zimbabwe or it is clearly a capitalist method of rural labour exploitation. The PSM methodology will help in giving the conclusions in the Zimbabwean case given the similarities of the rural households.

A number of authors have written on operation of contract farming in developing countries, Musara (2011) sought to determine the determinants of contract farming in small holder cotton producers in Zimbabwe but there have been no in-depth study on the effects of such private sector market activities in individual household's welfare.

Groch (1994) concluded that contract farming increases welfare since it solves market failures in the Agricultural sector but however Watt (1994) view it as a means of labour exploitation by the capitalist industry thus this study seeks to extent this debate to the Zimbabwean economy looking at the welfare impacts of the institution on households that choose to participate in private sector contracts on the basis of the general thinking that contract farming increases house- 
hold welfare because individual rationality dictates that if it does not increase welfare households will stop participating in the arrangement.

Bellemare (2010) using the data of Madagascar did a study on the welfare impacts of contract farming using several household indicators including income, income per capita, income per adult equivalent, income net of revenues and whether the household have received a loan in the past year. The study also used indirect impact of participating in contract farming on welfare by testing whether the household that participated have comparatively less volatile income measures. Extending this study to Zimbabwe and including more variables will help in the clear analysis of the effect of these private sector programmes on welfare in Southern Africa.

In order to measure the welfare gains on the households that participate on private sector programmes that include contract farming and private loans we compare them with their counterfactuals who do not participate to see welfare gains. There is still a big and growing debate on how to find the instrumental variable (IV) to identify the impact of participation on welfare gains that is a variable that explains participation but which is exogenous to household welfare to reduce the bias in measurement of welfare gains or loss due to participation.

Our study will adopt the propensity score matching by (Maertens, Swinnen, 2009) where there is the treatment and control groups and their difference that is the household that participates and the one that does not can be accounted on the basis of observables (Deheja and Wahba 2002). This method is most suitable for the Zimbabwean rural sector since most of the rural households have a number of similarities on farm sizes, whether conditions and economic opportunities.

The rural private sector includes a whole continuum of economic agents, ranging from subsistence or smallholder farmers, rural wageearners, livestock herders, small-scale traders and micro entrepreneurs; to medium-sized, local private operators such as input suppliers, microfinance institutions, transporters, agro processors, commodity brokers and traders; to other, bigger market players that may or may not reside in rural areas, including local or international commodity buyers and sellers, multinational seed or fertilizer companies, commercial banks, agribusiness firms and supermarkets. Associations of farmers, herders, water users or traders also constitute an important part of the private sector.

In rural economies, different private agents face different types of economic constraints that limit their potential for growth. Some of these constraints are intrinsic and include lack of access to knowledge and skills, while others are due to the external environment in which they operate (for example, an inappropriate policy and institutional framework, or inadequate rural transport infrastructure).

In either case, the constraints are such that rural economies are often perceived by many private-sector players as too costly and risky an option for investment. Typically, small farmers (to varying degrees and depending on the country) face constraints such as lack of technical, business or marketing skills; poor access to technology, financial services, and social and physical infrastructure (e.g. schools, training centres, health clinics, roads and markets); and low capacity to influence government policies. As a result, they are often unable to increase their productivity or produce a market surplus with which they can improve their cash income. Or if they are able to produce a surplus, they often lack the necessary information or skills to market it effectively and profitably.

While the number of workers in agriculture, including the self-employed, has stagnated in large parts of the world, the number of rural residents becoming non-farm rural employees continues to increase. Non-farm rural employment and self-employment are of particular significance to rural women and youth.

Agribusiness companies, too, may have an inadequate understanding of the rural population as a market for their services or as potential suppliers of produce. Where they do have rural clients, they may face high transaction costs. These include not only those costs associated with large numbers of dispersed small producers, but also those derived from a poor institutional, regulatory and policy environment. For example, legislation on market conduct is often lacking, contracts are not enforced, and information about the trustworthiness of small clients is not available. This means that investing in rural areas, and in particular contracting with small farmers or other rural dwellers, is often seen as too risky.

Due to the level of risk in rural business most private partnerships are in the agricultural sector which is highly supported by the govern- 
ment, private sector and NGOs Musara (2011). The main argument behind the vast support extended to agriculture in Zimbabwe is to improve welfare and reduce poverty in the economy.

Rukuni (2006) concluded that Agriculture is the cornerstone of the Zimbabwean economy contributing towards GDP and total export earnings and forming important linkages with the manufacturing sector. They concluded that $60 \%$ of the economically active population depends on agriculture on food and employment.

Contract farming has been a vibrant arrangement in the past decade due to reduced government funding towards small scale farmers due to funds constraints. It has been seen as a significant measure that can revive the agricultural sector in Zimbabwe in high value crops such as cotton, paprika and tobacco where returns to investment are high (Rukuni, 2006). Esterhuizen (2004) asserted that cotton from communal farmers contribute $70 \%$ of the national yield thus the communal farmers have been a target of contractors who provide them with inputs such as chemicals, seed, fertilizer and loans for labour payment.

Contract farming in Zimbabwe though viewed by some as not giving an advantage to farmers (Mugwagwa, 2005), it have been argued that contract farming ensures guaranteed markets to farmers which is an important factor in farming and in some instances it reduces the transport costs to farmers as the contractor collects the products from the farmer. In some instances contract farming has reduced viability due to a number of problems that it faces such as breach of contract due to side marketing, inadequate finance, poor quality produce and unfavourable producer prices from contractors.

Contract farming has expanded particularly in countries that have liberalized their markets through closing down marketing boards (Rukuni, 2006) concluded that contract farming has potential in Zimbabwe where small holder agriculture is widespread. The contract farming is usable by both the contractor and the farmer to mitigate risk (Makhura, Coertzee, Good, 1996).

Wooded (2003) acknowledged that contract farming has received increased attention as an institutional approach to commercialisation of smallholder agriculture to improve incomes and rural livelihoods and private sector led agriculture in Zimbabwe.
Cotton and tobacco are capital and labour intensive and improved production of these crops is based on the ability of the firm to finance farmers throughout the season since few households can afford the field work (Rukuni, 2006).

\section{MATERIALS AND METHODS}

Estimation of the welfare gain of adoption of household participation in private sector partnerships based on non experimental observations is not trivial because of the need of finding on counterfactual of intervention. We cannot observe the welfare outcome for those farmers who participated had they not participated. However, household participation is not randomly distributed to the two groups of the households (participators and non-participators), but rather the households themselves deciding to participate or not to participate based on the information they have. Therefore, participators and nonparticipators may be systematically different.

Following the leads of Asfaw (2010) two proxies are used to measure household welfare outcome in this paper, namely crop income and household consumption expenditure. Thus we estimate two welfare outcome functions for participators and another for non-participators. The study will employ non-parametric techniques, namely propensity score matching (PSM), to overcome the econometric problems and assess the robustness of our results.

Browyn and Moffioli (2005) noted that this provides a rigorous strategy of identifying statistically robust control groups of non-participants. Though the ideal evaluation of a program necessitates the creation of a treatment or control group it cannot be applied before the introduction of the program.

Propensity Score Matching (PSM) as first propounded by Rosebaum and Rubin (1983) is a method that is used to measure the impact of a program on the outcome of interest. PSM is a method used to reduce selection bias in the estimation of treatment or program effects with observational data sets. The methodology developed is used to assess a counterfactual in a given set of observational data just like in any scientific experiment where the same sample can be used to assess the impact on the outcome if the treatment was not administered.

The effect of treatment evaluation on policy formulations is direct because if an intervention 
is successful it can be linked to desirable social programs or improvements in existing programs through review. The aim of adopting such a process is to enable policy makers attain the objective or goal of intervention. According to Kassie (2010) the standard problem of treatment evaluation involves the inference of a causal connection between treatment and the intended outcome. Thus given a program we observe that:

$$
\left(Y_{i}, X_{i}, D_{i}\right) i=1, \ldots \ldots . . . . . . . .
$$

Where the dependent variable or outcome of interest is $Y_{i}, X_{i}$ is a vector of independent variables and $D_{i}$ is a binary variable indicating whether the individual household is a participator or not.

$$
D_{i}=\left\{\begin{array}{l}
=1 \text { ifthehouse holdpartic ipates } \\
=0 \text { otherwise }
\end{array}\right.
$$

It is the impact of a hypothetical change of $D_{i}$ on $Y_{i}$, holding the vector $X_{i}$ constant, that is of interest. In this case the outcome $Y_{i}$ is compared to the treatment and non-treatment states. Since no individual household is simultaneously ob- served in both states we cannot use the ones who did not receive the treatment in the sample as counterfactuals. The situation becomes that of missing data set. The method of causal inference can be tackled by creating a counterfactual. Therefore the question we tackle when applying PSM is to assess how the outcome of an average untreated individual household would change if such a household did not participate.

The idea of measuring the effects of adoption or treatment requires constructing a measure that compares the average incomes of the treated and non-treated groups. Rosebaum and Rubin (1983) define a propensity score as a condition probability of receiving a treatment given pretreatment characteristics. They show that if the exposure to treatment or adoption of technology is random within the cells defined by the values of the propensity score. Therefore given a population or sample of units the propensity score or the conditional probability of receiving a treatment given $X_{i}$ is:

$$
p(x)=\operatorname{Pr}[D=1 / x]=E[D / x]
$$

Once propensity scores are known we then can calculate the average effect of treatment on the treated (ATT) as follows:

$$
A A T=E\left[Y_{1 i}-Y_{0 i} / D_{i}=1\right]=E\left(E\left[Y_{1 i}-Y_{0 i} / D_{i}=1, p(x)\right]\right)=E\left(E\left[Y_{1 i} / D_{i}=1, p(x)\right]-E\left(Y_{0}\right) / D_{i}=0, p(x) / D_{i}=1\right) \ldots
$$

In equation $4 Y_{1 i}$ assumes if the household adopted new technology $Y_{0 i}$ is a counterfactual if the same household did not adopt technology. The hypothesis requires two assumptions: the conditional independence assumption and the assumption of unconfoundedness.

The first assumption states that conditional on $X_{i}$ the outcomes are independent of treatment. In other words, participation does not depend on the outcome.

Mathematically the representation states that the intervention outcomes are orthogonal of treatment conditional on the covariates given as follows:

$$
Y_{0}, Y_{1} \perp D / X
$$

The unconfoundedness assumption, which in some cases is referred to as balancing condition is necessary if we are to identify some population measures of impact (Rosenbaum, Rubin, 1983), given the overlap or matching assumption in 3 the assumption in 5 ensures that for each of the vector $X_{i}$, there exist both treated and nontreated cases. The propensity score measure can be computed given the data $\left(D_{i}, X_{i}\right)$ through a logistic regression.

Our $X_{i}$ shows the selection criteria: Educational background of household head; Income; Closeness to the chief's compound; Gender and age of household head; Total area of land utilised; Whether the land is under irrigation.

Thus for the unconfoundedness assumption it states that given the propensity score:

$$
D \perp X / p(x) \text {. }
$$

Equation 6 states that for individuals with the same propensity score, the adoption of technology is orthogonal or random, thus with the 
balancing condition, the conditional independence assumption given $\mathrm{X}$ implies conditional independence given $p(x)$ :

$$
Y_{0}, Y_{1} \perp D / X \Rightarrow Y_{0}, Y_{1} \perp D / p(x)
$$

Based on the above set of assumptions the PSM technique employs predicted probability of group membership that is treatment versus nontreatment group based on observed predictors usually obtained from a logistic regression to create a counterfactual group.

Using calculated propensity scores as defined in 3 is not enough to estimate average treatment effects of an intervention (Dehejia et al 2002). The reason is that the propensity score is usually a continuous variable and the probability of observing two units with the same propensity score is in principle not possible.

The propensity score allows the identification of farmers of similar covariates. The main purpose of propensity score is, given a treated farmer, to find an untreated farmer with similar characteristics. Accordingly, the difference in the outcome variable will be attributed to the treatment, and is denoted the average treatment effect. There are obviously some contentious issues, mainly the overlap and the unconfoundedness assumptions.

\section{SURVEY DESIGN, DATA AND RESULTS}

The data used for this study is from a primary data collection in two districts of Masvingo. These districts are Chiredzi and Masvingo rural communities which have similar weather conditions. During this survey, discussions were held with different stakeholders including farmers, traders and extension staff working directly with farmers. We did a random sampling of 315 households from each district and 516 families responded to the questionnaire.

The survey collected valuable information on several factors including household composition and characteristics, land and non-land farm assets, livestock ownership, household membership in different rural institutions, varieties and area planted, costs of production, yield data for different crop types, indicators of access to infrastructure and irrigation facilities, household market participation, household income sources, major consumption expenses and private partnership participation (whether the household received a loan or is into contract farming).

Table 1 below shows descriptive statistics of the respondents, the data shows that $50 \%$ of the households are on contract farming and $21 \%$ received loans while $29 \%$ did not participate in private partnerships' in the season 2010/2011.

From table 1 the survey also showed that those who entered into contract farming or received private loans on average had better educational background, were closer to the market and had agricultural extension services close to their farming plots. These finding are because firstly those who are educated have better knowledge on the importance of adequate funding in agricultural production. Secondly those close to extension services get encouragement to increase their production.

Table 1 - Description, units, and statistics for variables included in the study

\begin{tabular}{|c|c|c|}
\hline Variable & $\begin{array}{l}\text { Participators } \\
(\mathrm{N}=366)\end{array}$ & $\begin{array}{l}\text { Non-participators } \\
(\mathrm{N}=150)\end{array}$ \\
\hline Average net crop income (in USD) & 3452 & 1243 \\
\hline Total household income (in USD) & 1263432 & 186450 \\
\hline Average distance to village market (in $\mathrm{km}$ ) & 2.8 & 5.7 \\
\hline Distance to extension services (in $\mathrm{km}$ ) & 3.7 & 5.1 \\
\hline Average household head age (in years) & 36 & 54 \\
\hline Average household head education (in years of schooling) & 11 & 6 \\
\hline Average income from off-farm activities (in USD) & 239 & 451 \\
\hline Access to irrigation & 243 & 34 \\
\hline
\end{tabular}

The logit estimates of the participators propensity equation are presented in Table 2. The logit model has a McFadden pseudo $R^{2}$ value of 0.192 and correctly predicts 76 percent of adopters and 56 percent of non-adopters. Most of the variables are statistically significantly associated with participation in private sector partnerships. Farm size, occupation, and education are positively associated with adoption. 
Table 2 - Logit estimates of the propensity to adopt agricultural technology

\begin{tabular}{|c|c|c|}
\hline Variables & Coefficient & Robust std. error \\
\hline Ln (farm size) & $0.432 * * *$ & -0.075 \\
\hline Ln (distance to village market) & $-0.31 * * *$ & -0.076 \\
\hline Distance to main market & $-0.34 * *$ & -0.084 \\
\hline Distance to extension worker & $-0.46^{* * *}$ & -0.085 \\
\hline Age & $-0.044 * *$ & -0.157 \\
\hline Education & $0.80 * * *$ & -0.089 \\
\hline Off-farm income & -0.009 & 0.015 \\
\hline Constant & $-3.666^{* * *}$ & -0.694 \\
\hline \multicolumn{3}{|c|}{ Summary statistics } \\
\hline Pseudo R-squared & \multicolumn{2}{|c|}{0.192} \\
\hline Model chi-square & \multicolumn{2}{|c|}{185.16} \\
\hline Log likelihood ratio & \multicolumn{2}{|c|}{-413.6856} \\
\hline Non-adopters correctly predicted & \multicolumn{2}{|c|}{$56 \%$} \\
\hline Adopters correctly predicted & \multicolumn{2}{|c|}{$76 \%$} \\
\hline Number of observations & \multicolumn{2}{|c|}{516} \\
\hline
\end{tabular}

After estimating the propensity scores for participators and non-participators groups we check the common support condition. We find that there is considerable overlap in common support. Based on Table 2, among adopters, the predicted propensity score ranges from 0.339 to 0.999 , with a mean of 0.669 , while among nonparticipators, it ranges from 0.0129 to 0.898 , with a mean of 0.455 . Thus, the common support as- sumption is satisfied in the region of [0.0129, 0.999 ], with only a loss of 18 ( 0.035 percent $)$ observations from adopters.

The pseudo- $R^{2}$ is $19,2 \%$. This low pseudo$R^{2}$ suggests that the proposed specification of the propensity score is fairly successful in terms of balancing the distribution of covariates between the two groups.

Table 3 - Impact of adoption on crop income and consumption expenditure and Rosenbaum sensitivity analysis results

\begin{tabular}{|c|c|c|c|c|}
\hline \multirow{2}{*}{ Matching Algorithms } & \multirow{2}{*}{ Outcomes } & \multicolumn{2}{|c|}{ Mean outcome variables } & \multirow{2}{*}{ ATT (USD) } \\
\hline & & Participator & Non-participator & \\
\hline \multirow{2}{*}{$\mathrm{NNM}^{1}$} & Crop income & 886 & 543 & $\begin{array}{c}354 \\
(3.11)^{* * *}\end{array}$ \\
\hline & Consumption expenditure & 748 & 198 & $\begin{array}{c}311 \\
(3.14)^{* * *}\end{array}$ \\
\hline \multirow{2}{*}{$\mathrm{NNM}^{2}$} & Crop income & 895 & 343 & $\begin{array}{c}440 \\
(4.11)^{* * *}\end{array}$ \\
\hline & Consumption expenditure & 1687 & 1101 & $\begin{array}{c}456 \\
(3.14)^{* * *}\end{array}$ \\
\hline \multirow{2}{*}{ KBM } & Crop income & 2969 & 1453 & $\begin{array}{c}1433 \\
(3.21)^{* * *}\end{array}$ \\
\hline & Consumption expenditure & 1437 & 999 & $\begin{array}{c}546 \\
(2.14)^{* * *}\end{array}$ \\
\hline
\end{tabular}

$\mathrm{NNM}^{1}=$ single nearest neighbour matching with replacement, common support, and calliper (0.06).

$\mathrm{NNM}^{2}=$ five nearest neighbour matching with replacement, common support, and calliper $(0.06)$

$\mathrm{KBM}=$ kernel based matching with band width 0.06 , common support, and calliper (0.06).

Note: $* * *, * *, *$ is significant at $1 \%, 5 \%$, and $10 \%$, respectively.

Table 3 reports the estimates of the average participation effects estimated by NNM and KBM methods. As a sensitivity analysis, the table reports estimates based on the single and five nearest neighbours, and kernel estimator with one bandwidths. All the analyses were based on implementation of common support and calliper, so that the distributions of participators and non-participators were located in the same domain. As suggested by Rosenbaum and Rubin (1985), we used a calliper size of one-quarter of the standard deviation of the propensity scores.

The outcome variables are the net value of crop income per hectare and consumption expend- 
iture. Although the two matching algorithms based on the logit model produced different quantitative results, the qualitative findings are similar. The results indicate that participation in contract farming and private loans have a positive and significant effect on crop income and consumption expenditure.

The increase in crop income ranges from USD 886 to USD 2969 per hectare. This is the average difference in crop income of similar pairs of households that belong to different status (parti- cipators and non-participators). The increase in crop income helps adopters to increase their consumption expenditure and thus improve welfare.

Participation has impact on increasing the consumption expenditure with both matching algorithms techniques showing that participators have higher average consumption expenditures. The results show that adoption of technology increases income and consumption expenditure to households thus increasing welfare and reducing poverty.

\section{REFERENCES}

Bellemare, M., C. Barrett (2006), 'an Ordered Tobit Model of Market Participation: Evidence from Kenya and Ethiopia', American Journal of Agricultural Economics 88(2): 324-337.

Browyn, H., and A. Maffioli (2008), 'Evaluating the Impact of Technology Development Funds in Emerging Economies: evidence from Latin America,' a Technical Report available at http://hd1.handle.net/10086/15999.

Dehejia, R. H., and S. Wahba (1999), 'Causal Effects in Non-Experimental Studies: reevaluating the evaluation of training programs', Journal of the American Statistical Association, 94, 1053-1062.

Dorward, A., E. Chirwa, V. Kelly, T. S. Jayne, R. Slater, and D. Boughton (2008), 'Evaluation of the 2006/07 Agricultural Input Subsidy Programme, Malawi', Final Report, Ministry of Agriculture and Food Security, Lilongwe: March.

Rosenbaum, P., and D. B. Rubin (1983), 'The Central Role of Propensity Score in Observational Studies for Causal Effects,' Biometrika, 70, 227-240.

Dehejia, H.R., and Wahba, S. (2002). Propensity score matching methods for nonexperimental causal studies. The Review of Economics Statistics 84(1): 151-161.

Grosh, Barbara (1994), "Contract Farming in Africa: An Application of the New Institutional Economics," Journal of African Economies 3(2): 231-261.
Maertens, Miet, and Johan F.M. Swinnen (2009), "Trade, Standards, and Poverty: Evidence from Senegal," World Development 37(1): 161-178.

Musara et al 2011, 'determinants of smallholder cotton contract farming participation in a recovering economy: empirical results from patchway district, Zimbabwe.

Esterhuizen, E. (2004). Competition and Coordination in Zimbabwe Cotton Sector 2001-2004. Retrieved from www.aec.msu.edu.

Makhura, M.T., Coertzee, G.K. and Good, F.M. (1996). Commercialization as a strategy for reconstruction in Agriculture. Agrekon 35(1): pp 35-40.

Mugwagwa, I. (2005). JIMMAT Development Consultants, 2005. STABEX Cotton Sector Study Final Report. Harare.

Rukuni, M. Tawonezvi. P., Eicher C; Munyuki-Hungwe M and Matondi, P. (2006). Zimbabwe's Agricultural Revolution Revisited, University of Zimbabwe Publications, Harare.

Wooded J.J. (2003). Potential of contract as a mechanism for commercialization of Smallholder agriculture. The Zimbabwe Case Study. Harare. Retrieved from www.fao.org. 